\title{
SRI LANKAN CHILDREN: ARE WE PROVIDING A CHILD \\ FRIENDLY FORENSIC SERVICE?
}

\section{Paranitharan $\mathbf{P}^{1}$ \& Perera WNS ${ }^{2}$ \\ Senior Lecturer, Department of Forensic Medicine, Faculty of Medicine, Ragama, Sri-Lanka ${ }^{1}$ Head, Department of Forensic Medicine, Faculty of Medicine, Ragama,Sri-Lanka ${ }^{2}$}

\section{Introduction}

A healthy child with physical and mental well being is important for a bright future of an independent nation. This is achieved with the contribution of several professionals with special interest in child well being. In Sri Lanka the National Child Protection Authority (NCPA) provides a yeoman service with regard to child development and well being. The World Health Organization estimates that globally some 40 million children aged 0-14 years suffer some form of abuse and neglect requiring health and social care. ${ }^{1}$ In Sri Lanka the statistics with regard to child abuse cases may not reflect the true number since many cases go unreported to a central information collecting centre.

The child abuse cases may involve a wide spectrum of cases including physical abuse, sexual abuse, emotional abuse and neglect. There may be cases which need mandatory institutional care. ${ }^{2}$ Therefore establishing a system which is child friendly with minimal discomfort to the victim is important.

\section{Objective}

To do a descriptive study of the existing forensic service with literature review in relation to Sri Lankan children

\section{Discussion}

The basic underlying concept involved in this paper is to propose a system which is child friendly. The true meaning of child friendliness is where the best interest of the child is always maintained from the point of entry till the completion of medico legal examination. Therefore a system which is in operation at Dundee, United Kingdom is considered as a model structure based on which the child care facilities available in Sri Lanka are analyzed with a genuine interest of the upliftment of care to be provided to the Sri Lankan children. Further this paper will also strengthen the concept of multidisciplinary approach which is the main functioning pillar in the British system.
The literacy levels of the Sri Lankan and the British population is almost in par which is usually the main barrier when a country tries to introduce a new administrative system. Therefore Sri Lanka is better positioned and should be receptive of any reasonable changes with time to come. The first step where an abused child is taken into a system is the reporting. The British reporting standards and the Sri Lankan are almost similar but in Dundee the school teachers, staff attached to day care centres and the General Practioners are more involved in reporting cases of child abuse. The General Practioners are usually the first level of contact in the British system and the abused victims are reported promptly by them. Each family in Dundee is assigned a social care worker who is responsible of the well being of the family including the children. The social care worker is already in the system and he or she does not necessarily be appointed to look after an abused child.

When an abused child is detected or reported the next step involves the investigation and management of the child. There are detectable differences in the British and Sri Lankan approach towards an abused child. The concept of child friendly investigation and management is well established in the British system. Whenever information is received regarding an abused child the child is taken to a 'Child Protection Unit' which is a residence that cannot be differentiated from other neighbouring houses. The unit is manned by investigating police officers in plain cloths. The social worker assigned to the family is contacted immediately. If there is no social worker a social worker is assigned to the family. The social worker plays a key role in the management and decision making process of the child coordinating with other stake holders and enhancing the multidisciplinary approach in a child friendly environment. In complex cases a case conference is organized by the social worker with the participation of the key officials. The police officers, who are well trained, take the history from the child in a friendly environment. The child will not feel any difference that he or she is accommodated in a hostile environment. Further the examination of an abused child is done as a joint examination by the paediatrician 
and the forensic physician at the Family Protection Units. If a child needs hospital care the joint examination will be done at the hospital. The paediatrician will act as the lead clinician directing referrals and playing a major role in the management. ${ }^{3}$ The part of the forensic physician is limited to only give opinion regarding the injuries. In the British multi disciplinary approach the Forensic Physician has only a small role to play. The Forensic Physician may have to spend several hours at the Family Protection Units even with a child with minimal injuries just to make sure that the child friendly concept is adhered. In comparison the Sri Lankan system of dealing with victims of child abuse, where the child usually gets admitted to a Paediatric ward or a Gynaecology ward and he or she has to stay with other children of different ailments or with adults. The child would be taken to different specialists for various referrals. The existing system may prolong the stay in hospital and further traumatize the child since the confidentiality of the incident would be difficult to maintain as the child had to mix with others in a common ward. To minimize these issues we can improve on the child friendly concept and be a participant of the multidisciplinary team the concept of which is discussed below in detail.

The affected child in Britain is handed over to foster parents without delay if the perpetrators are family members. The decision is taken by the police and social worker within a short period of time. The procurator fiscal the equivalent of state counsel in Sri Lanka is involved with all cases of child abuse in Britain. He or she has first hand knowledge of all the cases from day one. He will be in a better position to provide guidance to the police and other stake holders with regard to legal issues.

The Sri Lanka as a nation with high literacy rate, to develop a child friendly system with multidisciplinary approach is not a dream. We can develop a better system than the British if we spend some time and pool our resources to adapt a socially and nationally acceptable system. The National Child Protection Authority has already done tremendous work with regard to reporting and awareness of child abuse cases. They can help in coordinating the new system of child friendly and multidisciplinary approach in a hospital environment. We propose to establish 'Child Protection Units' in teaching hospitals which will be managed by 'Child Protection Committees' (CPC) with multidisciplinary approach. ${ }^{4}$ The child protection units will be located inside hospital premises with a homely environment with child play areas. This unit will not remind the child that he/she is inside a hospital. This unit will be placed under the supervision of a senior staff nurse who will be responsible for the child well being and will function as a coordinator between the police, child probation officer, Forensic physicians and Paediatrician. She will be also responsible for coordinating special referrals of the child. In this unit all the consulting staff will be visiting the child and the child would not be taken to different places. The CPU will have all the facilities needed for a proper examination and management. The composition of the child protection committee can involve the investigating police officers, child probation officers, Community Paediatrician, Forensic Physician, representative from Attorney Generals department, representative from Education department and social workers with special interest in child care. The child protection committees will see that a child friendly environment prevails all the time in the hospital premises. There will be absolute confidentiality of cases admitted to this unit. This unit can cater children up to 18 years. The CPC will be responsible in developing policies, procedures, protocols, management information, quality assurance, practice, training and staff development. $^{5,6}$ There may be reservations among some academia with regard to utilizing hospital resources for the victims of child abuse. The authors feel this is a plausible alternative in comparison to a safe house like Dundee.

Later we can spread this system to the base hospitals as well as smaller hospitals. In other hospitals we have to identify the team members for CPC. The CPC should give the monthly returns to the health ministry for proper data collection. The Centre for Child Health and Care (CCHC) at the health ministry may coordinate the activities of CPC at the national level with an established advisory committee comprising members from the Police, Office of the JMO, Attorney General, Social Services Department, Non Governmental Organisations, and Specialists from Paediatrics, Obstetrics \& Gynaecology and Psychiatry. Including all stake holders to this centre for child health and care will help in policy making and to provide expert advice if there is any problem while managing the case. The centre for $\mathrm{CHC}$ will maintain a child protection register with confidential list of names of children who are believed to be at risk of significant harm. ${ }^{5}$ This may not reflect the true cases of child abuse. The statistics of child abuse cases would be gathered from the different child protection units distributed in the island with the central record centre located in the Child Heath and Care premises at the ministry of Health. 
We would like to propose this system to be adapted for future Sri Lanka to provide a child friendly forensic and other related services. As Forensic Physicians we can play a pivotal role by acting as clinical audits to see whether the system is functioning smoothly without any hassle.

\section{Conclusion}

In conclusion a better system which is child friendly with multidisciplinary approach is the ultimate goal of this paper. In future Sri Lanka the children of this nation would be mentally and physically stable to lead this country towards prosperity.

\section{Acknowledgement}

We would like to appreciate the valuable information provided by Dr BPP Perera regarding the services available in Dundee, Scotland for an abused child.

\section{Reference}

1. WHO report of the consultation on child abuse prevention, 29-31 March, 1999.Geneva: World Health Organization; 1999

2. Terens SR, Wilson C. An update on child abuse and neglect. Current Opinion in Paediatrics. 2004 Apr; 16(2):233-7

3. www.dundee protects.co.uk last accessed on 3.1.2011

4. www.Scotland.gov.uk last accessed on 3.1.2011

5. www.young scot.org last accessed on 3.1.2011

6. Amanda SN, Belle Zou, Michael P et al. Improving Child protection in the emergency department: A systematic review of professional interventions for health care providers. Academic Emergency Medicine. 17(2): 2010 p $117-125$ 